\title{
Reflections on risk and resilience in adolescence
}

\author{
Sandy Jackson, Michel Born and Marie-Noel Jacob
}

Almost 50 years ago, Werner (1948) described development as involving a movement from relatively diffuse, undifferentiated patterns of behaviour towards forms of organization which are more structured, articulated and complex. This process involves the emergence of new organizational structures which, as they become consolidated and more distinct, also move into new forms of hierarchic organization relative to each other. In the context of adolescence, for example, this process means that while our attention is directed towards a specific aspect of development such as identity. social development or pubertal development, we cannot afford to ignore the fact that each of these is intimately related to the others in a variety of complex ways. Stattin (1995) has summarized this situation succinctly by suggesting that there is a strong argument for making the "whole person" the focus of adolescent research.

This argument is even more potent when we consider Werner's ideas about differentiation and hierarchic integration still further. Werner argues that as development proceeds and further reorganizations occur, earlier developmental structures are embraced by and become involved in later structural forms through the process of hierarchic integration. These earlier structures do not disappear-i.e. the form of organization which occurred at a prior stage in development is not itself reorganized-but continue more or less intact within the new hierarchic organization. This means that the effects of previous negative experiences may be carried forward into successive developmental organizations and if the individual is subjected to stress, may lead to the expression of inappropriate forms of response (Sroufe and Rutter, 1984). The unexpected occurrence of depression or the sudden emergence of eating problems in an individual who has always appeared welladjusted may well be rooted in this type of phenomenon. Similarly, such processes may account for situations where people react in an unexpectedly competent way to particularly adverse types of experience.

During the past two decades, such ideas have helped to move the focus of much developmental research towards issues such as the relationships between continuity and change in development, or the significance of the different types of transitions which development brings (e.g. Collins, 1990). This more process-oriented approach contrasts with the largely descriptive studies which were a typical feature of much of the developmental research carried out in the first 50 years of the present century (e.g. Gesell, 1948: Gesell et al., 1956). A similar approach was also applied in studies concerned with deviant forms of development. The work of the Gluecks (e.g. Glueck and Glueck, 1962), for example, involved comprehensive descriptions of the characteristics and situations of delinquents. Such work modelled the taxonomies of psychological disorders which dated back to Kraepelin (1915) and which underpinned clinical approaches throughout the first

Reprint requests and correspondence should be addressed to $S$. Jackson. Department of Developmental Psychology. University of Groningen, Grote Kruisstraat 2/1, 9712 TS Groningen, The Netherlands.

0140-1971/97/060609+08/\$25-00/0/ad9701140 1997 The Association for Professionals in Services for Adolescents 
half of the current century. The influence of such work is still evident today in the DSM classification systems (Achenbach, 1984).

Clear description of a problem provides a basis for distinguishing one type of problem from another and this process of discrimination can be seen as the first step towards selecting appropriate approaches directed towards intervention. From this perspective, the descriptive approaches have always carried the implication that effective identification of a problem is linked to some form of subsequent therapeutic action. It is only a short step from this idea to the notion that descriptive categories may also offer a basis for early identification of a problem and may therefore fulfil a preventive role. This notion led readily to attempts to identify the characteristics of different types of populations who could be seen as being "at-risk" of a particular type of problem such as delinquency (Stott, 1966) or emotional disturbance (Sanson et al., 1991). A variation of this approach involved selecting a specific risk indicator such as maternal depression (Fergusson et al., 1995) or adoption (Seglow et al., 1972) and then studying the developmental course followed by the group of children concerned.

Studies of children at-risk led quickly to the recognition that certain children did not succumb in the same way as others to maladaptive behaviour. Such children seemed to be in some way protected against the negative effects of parental, social or environmental factors, so that their development was able to proceed apparently unimpaired by diffficulty. Recognition of this phenomenon led to the notion that they might be protected because they were more resilient than their peers. They could respond more effectively in difficult circumstances and by doing so could resist the types of difficulties experienced by their peers.

The idea that certain factors in development may offer protection against future problems and the related idea that resilience may be an important element in this situation encouraged a range of studies some aimed at identifying possible protective factors and others at examining the differences between resilient and non-resilient children. Almost all of the studies in this special edition fall into the latter category. Each article is based on a paper which was originally presented at the fifth biennial conference of the European Association for Research in Adolescence (EARA ${ }^{\prime}$ ) which took place in May 1996 at the University of Liege in Belgium. Risk and resilience were two topics which together represented one of the central themes of the conference. The seven articles published in this special edition represent different ways of approaching the study of risk and resilience. Each considers a particular group which may be seen as being potentially at-risk, with some laying greater emphasis on risk factors, while others concentrate primarily on resilience.

The initial paper by Rosnati and Marta is concerned with the problems which may arise with adopted children and, specifically, children with a different nationality from that of their adoptive parents. Adopted children are a group which can be seen as presenting a variety of potential risks (Hersov, 1990; Howe, 1997). One or other of the adoptive parents may have difficulty in accepting the new child. Adoption may take place following a period in which the infant is subjected to a range of other experiences not all of which may be positive (Maughan and Pickles, 1990). As the child develops and becomes aware of his/her adoptive status, tensions may arise between parents and child, or the young person may experience difficulties in social relationships and friendship formation (Hodges and Tizard, 1989).

'Details of EARA and of how to join can be obtained from Dr Peter Noack. Department of Psychology. University of Jena. Am Steiger 3/1. Jena, D-07743 Germany. E-mail S7NOPE@RZ. UNI-JENA DE 
Within this context, children who are of a different nationality from that of their adoptive parents represent a specific sub-group which might be seen as being even more atrisk than children adopted by parents of the same race. Rosnati and Marta point out that the few studies which have compared intra-racial and inter-racial adoption were able to identify few clear differences. However, they also point to the lack of relevant research concerning adopted adolescents and suggest that there are good reasons for paying special attention to the possible problems experienced by young people at this stage of development. Their study compares inter-racial adoptees with adolescents living with their natural parents. The results show interesting differences between non-adoptive and interracial adoptive families with regard to the level of support given and received. The fathers of adopted children are more involved in child-rearing activities and adoptive parents have more supportive relationships with their children. However, adoptive mothers experience more problems in communication with their children than is the case with non-adoptive parents. Where risk of maladjustment is concerned, the results indicate that the quality of the mother-child relationship is the most important basis for predicting psychosocial risk. This finding contrasts with that for non-adoptive children for whom the quality of father-child communication and support from both parents is of central importance.

Taken together, the results indicate that there are important differences between the ways in which the two different types of family function and that such differences even extend to the interaction patterns which fulfill a protective role for the adopted as opposed to the non-adopted children. Besides carrying important implications for support services working with such families, these findings raise interesting issues with regard to the ways in which specific types of family systems become established and influence the development of the child in their own particular ways.

Adolescence is generally seen as a period when relationships with peers take on new significance and when new patterns of relationships are developed (Berndt and Perry. 1986; Jackson and Rodriguez-Tome, 1993). Kirchler et al. (1993) have shown that coping with developmental tasks is heavily dependent on the nature of the adolescent's identification with parents and peers. Where peers were concerned, they were able to show that the nature of the group with whom the adolescent is involved is of subordinate importance. What is important is the type of relationship that is formed with the group and it is this which has important implications for the developmental process. High identification leads to greater emotional and informative support from the group, while low identification is associated with a more marginal status. The latter group tends to have lower levels of selfesteem and cope less effectively. These results conform with results of other studies concerning the positive roles played by friends in providing social support and help in coping with problems (e.g. Seiffge-Krenke and Shulman, 1993).

Despite this evidence of the positive effects of identification with peers, it is important to bear in mind that in certain group contexts identification may have negative effects. Identification with delinquent groups is one example of this (Emler et al., 1987) and Stattin and Magnusson's (1990) findings on the effects of early maturation on girls' subsequent development provides another more specific example. In addition, there is evidence that children who are rejected by their peers-i.e. have problems in establishing and maintaining friendships and close relationships with peers-are more likely to experience one or more of a variety of disorders at some subsequent stage in their development (Kupersmidt and Coie, 1990). These studies do not contradict the general message that positive peer relationships are a significant factor in healthy development in adolescence. 
but they do emphasize the need to examine more closely the nature of the relationships formed, with whom they occur, how they relate to previous developmental history and their implications for future development.

The article by Pawlby, Mills, Taylor and Quinton in this special edition is an example of how useful more specifically focused research can be. Their study compares the friendships of an "at-risk" group of girls with those of girls whose background gave no indication of future risk. They were able to identify important differences between the two groups with regard to both romantic and non-romantic friendship patterns. For the "at-risk" group. friendships of each type showed similar patterns in that they occurred with males and fernales who were at a different life stage from that of themselves and in a context where education was not an area of shared activity. The high-risk girls also started solo-dating at an earlier age than their peers and were more likely to have engaged in sexual intercourse at an early stage in the relationship. Pawlby et al.'s somewhat bleak finding is that there appears to be considerable continuity between problems earlier in life and the nature of friendships formed in adolescence. However, the finding did not apply to all of the high-risk sample. Some girls had established friendship patterns resembling those of the control group girls. This raises questions as to the factors contributing to this, as opposed to the prevailing pattern. Were these differences related to the types of peer acceptance/rejection processes discussed by Kupersmidt and Coie (1990)? Unfortunately, the data do not permit an answer to this question. However, they underline yet again the need to engage in more detailed research into the ways in which friendship patterns and group processes may interact so as to provide forms of social support which later contribute to outcomes which may be positive or negative.

The articles by Buysse and by Bender and Losel maintain the focus on adolescent relationship patterns. Like Pawlby et al., Buysse compares young people with a background of professional care with a normal group of adolescents. Her main interest, however, is not in friendship patterns as such, but rather in how social networks, personal resources and environmental risk relate to the occurrence of behaviour problems. Her findings are consistent with our remark in an earlier part of this article "that in certain group contexts identification may have negative effects." Where the group is non-deviant and offers high support, behaviour problems are less likely to occur. The opposite is true when the group offering high support is deviant. Questions arise here with regard to the direction of effects. Does the group adversely influence the behaviour of the individual in a negative direction, or does the presence of particular personal characteristics lead the young person to select a deviant group? Buysse interprets her findings as giving support to the latter position. If her interpretation can be supported, it indicates that ideas about peer influences in delinquency may have to be modified so as to take greater account of interactions between individual and peer-group characteristics.

Bender and Losel's study is somewhat similar to that of Buysse in that it is also concerned with peer relations and social support. It differs however in the methods used and in that the focus is on young people from residential foster-care establishments. Some of the young people concerned could be characterized as successful adaptors while the remainder had developed severe behaviour problems. These two sub-groups were compared with specific reference to a set of social support variables: social embeddedness, perceived support and enacted support.

Consistent with Buysse's study, social support from a peer group did not necessarily emerge as protective-neither males nor females showed an alteration in deviant behaviour 
when they described themselves as integrated into and supported by the peer group. Bender and Losel's findings also indicate that lack of peer group membership and low satisfaction are linked with later aggression and delinquent behaviour, a pattern which is in line with Kupersmidt and Coie's (1990) results.

Bender and Losel's group comprised both boys and girls so that they were able to take account of possible sex differences as well as specific sex-related behaviours. Girls with no boyfriend showed stable patterns of externalizing behaviour, whereas the presence of a boyfriend proved to be protective for the more aggressive girls. The size of the girl's social network also emerges as a variable whose effects differ according to the level of antisocial behaviour. Involvement in a small social group fulfils a protective function for the most antisocial girls whereas for the less antisocial it is a risk factor. Bender and Losel speculate that this difference may arise from the tendency of more antisocial girls to be more influenced by misperceptions of closeness and non-reciprocity. This interpretation fits well with a perspective which recognizes that differences in level of soclal cognitive development may lead to mismatching of ideas, inappropriate reactions and interpersonal misunderstanding (Jackson, 1993). Such patterns might be expected to occur more markedly in young people whose experience and understanding of social relationships has been impaired by adverse events at earlier stages in their social development.

Each of the different articles which we have discussed has used a relatively global approach in defining risk and resilience. For example, Rosnati and Marta, Pawlby et al. and Buysse compared their "at-risk" groups with normal adolescents, while Bender and Losel used adaptation as a criterion for dividing their residential group into resilients and deviants. Born, Chevalier and Humblet point out that there is a need to be precise about the sort of variables which define resilience because failure to do so carries the risk that young people are placed in an inappropriate category or that researchers studying resilient youth are actually working with different types of groups. Their study attempts to meet this need by defining five criteria of risk and a set of criteria for resilience. The great advantage about such an approach is that it makes comparison between results obtained from different groups possible without the risk that the basis for defining the groups is quite different.

The authors also suggest that a clearer definition of terms provides a sounder basis for distinguishing between different types of delinquents and thus avoids the danger of defining a "transitory" delinquent as a "career" delinquent or vice versa. With regard to research, it also offers a basis for defining the factors which predict future delinquent careers and their seriousness and those which indicate the likelihood of desisting from delinquent behaviour. Born et al. suggest that their data point to the personal characteristics of the individual rather than broader family factors as being central to resilience. One might speculate. however, that at some point there must be some link between family factors and individual characteristics whereby particular characteristics are strengthened or weakened by experiences occurring during the course of intra-familial development. Bandura's ideas about how children develop a concept of their own efficacy in coping with problems (Bandura, 1981), for example, require contexts which provide positive feedback. As we have seen, some of the other articles have emphasized the importance of positive ideas concerning self as being central to the resilient response. It is difficult to imagine a situation where the home does not contribute in some measure to the sort of feedback process which Bandura describes and, hence, to the development of favourable self-related ideas.

In her article, van Welzenis is centrally concerned with how socially vulnerable and delinquent boys think about themselves with specific reference to school and leisure 
activities. She argues that much research on self-concept and delinquency has been too simplistic because it has considered self-related ideas in an undifferentiated fashion. Her study distinguishes between different domains which are relevant to adolescents, such as school and leisure time and also considers differences between conventional and nonconventional characteristics and skills.

The results indicate that school success is associated with self-related ideas which are linked with school and conventional characteristics. Boys who had not managed to establish themselves in a peer-group tended to employ the same sort of ideas. On the other hand, lack of success at school or having been institutionalized because of delinquency is associated with a self-concept oriented towards leisure and non-conventional characteristics. These results appear to be consistent with Bandura's ideas (op. cit.), though it is not clear whether the mechanisms involved are the same as those which he postulated. They point to the need to avoid the assumption that self-related ideas remain consistent across domains. They suggest that concepts like risk and resilience should be carefully defined, a message which fits in with the plea of Born et al. for clear definition of what is meant when such concepts are employed in research contexts.

Coslin's article differs from the rest in that it is primarily concerned with young people who are potentially in an at-risk situation as evidenced by their behaviour at school. It does not attend directly to risk factors or to resilience. Instead it seeks to examine how disruptive behaviour is regarded by those who engage in it and by those who witness it without being involved. It also considers young people's views of the sort of sanctions which are appropriate in response to such behaviour. In focusing upon the young people's attitudes to disruptive behaviour, it can be described as attempting to provide a picture of the psychological context within which patterns of behaviour which may place young people at-risk, or may signal their at-risk status, can arise.

The results point to a context within which young people's ideas about the response appropriate to disruptive behaviour is influenced by the young people's knowledge of the perpetrator of the behaviour. This effect is stronger where the judgement is made by a young person who has also been involved in disruptive behaviour. Previous involvement has the effect of heightening tolerance and this presumably facilitates the acceptance of a school climate in which the emphasis falls less on education and where further personal involvement in disruption is more likely to re-appear. In the light of some of the other articles, one might think of this as a context in which risk factors can be further subdivided, the nature of social support can be extended and misperceptions of behaviour and its significance can arise.

Taken together, the different articles in this special edition provide a broad view of how the notion of risk need not be restricted to one problem such as delinquency, but can be applied to young people in a variety of settings. One might think, for example, of adolescents suffering from chronic sickness, or physical handicap or from family contexts involving mental-illness or absence of a parent. Risk can also be thought about in different ways. In some cases, it might be the risk of delinquency or recidivism, in others the risk of social isolation, in still others the future emergence of depression or eating disorders.

Rutter (1996) has pointed to the need to distinguish between "risk indicators" and "risk mechanisms." The articles in this special edition have concentrated on the former, only implicit reference having been made to the latter. At the present stage of research it is perhaps appropriate to confine ourselves to indicators and how these might tie in with particular forms of adaptive response. Ultimately, of course, it will be essential to focus upon 
the mechanisms which lead from risk to effective or ineffective adaptation. Insights into both indicators and mechanisms appear to be fundamental to any proper understanding of related concepts such as resilience.

While the concept of risk can be thought about too narrowly, the reverse is perhaps true of resilience. Too often it appears to be discussed as if it is a general psychological characteristic - if you have it you are less likely to succumb, while if you lack it problems can be expected. Such a view is mistaken. As Luthar and Zigler (1991) have pointed out, competence in high-risk situations is not necessarily an indication of an ability to remain invulnerable to internalizing symptoms and/or health-related problems. The implication of this is that we need to be more specific in how we think about and apply a term such as resilience: research needs to define domains in which coping proves to be successful and those where failure occurs (Luthar, 1993). As Luthar points out, this requires clear definition of the central constructs which are employed. It also requires attention to the processes and personal characteristics which together serve to modify risk in a more favourable direction.

The papers in this special edition have made some progress in attending to these requirements for a comprehensive study of risk and resilience in adolescent development. Further work remains to be done, but fortunately there is now a clearer picture of the directions which such work should take.

\section{References}

Achenbach, T. M. (1984). Developmental psychopathology. In Developmental Psychology: an advanced textbook. Bornstein, M. H. and Lamb M. E. (Eds). Hillsdale, NJ: Lawrence Erlbaum Associates.

Bandura, A. (1981). Self-referent thought: a developmental analysis of self-efficacy. In Social Cognitive Development: frontiers and possible futures. Flavell, J. and Ross L. (Eds). Cambridge: University of Cambridge Press.

Berndt, T. J. and Perry, T. B. (1986). Children's perception of friendship as supportive relationships. Developmental Psychology, 22, 640-648.

Collins, W. A. (1990). Parent-child relations in the transition to adolescence. In From Childhood to Adolescence: a transitional period, Montemayor. R., Adams, G. and Gullotta. T. (Eds). London: Sage.

Emler, N., Reicher, S. and Ross, A. (1987). The social context of delinquent conduct. Journal of Child Psychology and Psychiatry, 28, 99-109.

Fergusson, D. M., Horwood, L. J. and Lynskey, M. T. (1995). Maternal depressive symptoms and depressive symptoms in adolescence. Journal of Child Psychology and Psychiatry, 36, 1161-1178.

Gesell, A. (1948). Studies in Child Development. New York: Harper \& Row.

Gesell, A., Ilg, F. L. and Ames, L. B. (1956). Youth: the years from ten to sixteen. New York: Harper \& Row.

Glueck, E. and Glueck, S. (1962). Family Environment and Delinquency. Boston: Houghton Mifflin.

Hersov (1990). The seventh Jack Tizard memorial lecture. Aspects of adoption. Journal of Child Psychology and Psychiatry, 31, 493-510.

Hodges, J. and Tizard, B. (1989). Social and family relationships of ex-institutional adolescents. Journal of Child Psychology and Psychiatry, 30, 77-97.

Howe, D. (1997). Parent-reported problems in 211 adopted children: some risk and protective factors. Journal of Child Psychology and Psychiatry, 38, 401-411.

Jackson, A. E. (1993). Social behaviour in adolescence: the analysis of socjal interaction sequences. In Adolescence and its Social Worlds, Jackson, A. E. and Rodriguez-Tome, H. (Eds). Hove, Sussex: Lawrence Erlbaum Associates.

Jackson, A. E. and Rodriguez-Tome, H. (1993). Adolescence and its Social Worlds. Hove, Sussex: Lawrence Erlbaum Associates. 
Kirchler, E., Palmonari, A. and Pombeni, M-L (1993). Developmental tasks and adolescents relationships with their peers and family. In Adolescence and its Social Worlds, Jackson, A. E. and Rodriguez-Tome, H. (Eds). Hove, Sussex: Lawrence Erlbaum Associates.

Kraepelin, E. (1915). Compendium der Psychiatrie, 8th Edn. Leipzig: Abel.

Kupersmidt, J. and Coie, J. (1990). Pre-adolescent peer status, aggression and school adjustment as predictors of externalising problems in adolescence. Child Development, 61, 1350-1362.

Luthar, S. S. (1993). Annotation: Methodological and conceptual issues in research on childhood resilience. Journal of Child Psychology and Psychlatry, 34, 441-453.

Luthar, S. S. and Zigler, E. (1991). Vulnerability and competence: a review of research on resilience in childhood. American Journal of Orthopsychiatry, 61, 6-22.

Maughan, B. and Pickles, A. (1990). Straight and Devious Pathways from Childhood to Adulthood. New York: Cambridge University Press.

Rutter, M. (1996). Psychosocial adversity; risk, resillience and recovery. In Conflict and Development in Adolescence, Verhofstadt-Deneve, L., Kienhorst, I. and Braet, C. Leiden University: DSWO Press.

Sanson, A., Oberklaid, F., Pedlow, R. and Prior, M. (1991). Risk indicators: assessment of infant predictors of pre-school behavioural maladjustment. Journal of Child Psychology and Psychiatry. 32, 609-626.

Seglow, J., Pringle, M. K. and Wedge, P. (1972). Growing up Adopted. Windsor, U.K.: NFER.

Seiffge-Krenke. I. and Shulman, S. (1993). Stress coping and relationships in adolescence. In: Adolescence and its Social Worlds, Jackson, A. E. and Rodriguez-Tome (Eds). Hove, Sussex: Lawrence Erlbaum Associates.

Sroufe, L. A. and Rutter, M. (1984). The domain of developmental psychopathology. Child Development, 55, 17-29.

Stattin. H. (1995). Introduction: The adolescent is a whole person. Journal of Adolescence, 18, 381-386.

Stattin, H. and Magnusson, D. (1990). Paths Through Life, Vol. 2. Pubertal maturation in female development. Hillsdale, NJ: Lawrence Erlbaum Associates.

Stott, D. H. (1966). Studies of Troublesome Children. London: Tavistock Publications.

Werner, H. (1948). Comparative Psychology of Mental Development. New York: International Universities Press. 